\title{
YOUTH EMPLOYMENT IN REGIONAL ECONOMIC DEVELOPMENT
}

\author{
Svetlana Tsokhla \\ Yelena Polishchuk \\ V.I. Vernadsky Crimean Federal University, Simferopol, Russia
}

The study is offering an improvement of organizational-economic mechanism to facilitate the process of effective youth employment with the aim of achieving sustainable socioeconomic development of the Republic of Crimea.

The methodological basis of the study is an integrated approach to studying the youth employment process, with its direct impact on professional expectations and fuller integration into society.

In order to study regional labor market we have conducted a questionnaire survey of organizations' (enterprises') managers and the youth of several age groups. The purpose of the survey was to collect information on the opinions and expectations of employers regarding the quality of training of young specialists under today's conditions, as well as on the preferences of young people about the effectiveness of the employment process. Stemming from the results of this survey we have found significant imbalances that affect the efficiency of the employment process overall.

Keywords: youth, labor market, employment, labor potential.

\section{Introduction}

The issue of adjustment of the existing organizational-economic mechanism affecting the process of effective employment of the youth in the Republic of Crimea is highly topical, because youth is the main source of resources for the labour market, due to its active participation in the economic growth of the region.

The current situation at the youth labour market in the Republic of Crimea is rather intense: about $40 \%$ of young people are unemployed. Therefore, Crimean labour market as

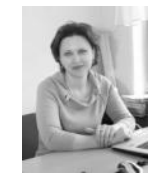

\footnotetext{
Svetlana Tsokhla

Doctor of Economics, Associate Professor, Head of the Chair Department of business management, 1Institute of Economics and management, V.I. Vernadsky Crimean Federal University, Simferopol, Russia

Research Interests: mechanisms of economic management, economic development strategy, investment, innovation, transformation of the resort and recreation area, economic diagnostics, forecasting, controlling. She is the author of 89 scientific and educational publications, including three monographs and three manuals for students.

E-mail: svetlana.tsohla@gmail.com

Polishchuk Elena

Candidate of economic sciences, senior lecturer, Department of business management Management department, V.I. Vernadsky Crimean Federal University, Simferopol, Russia Research Interests: Analysis of the shadow economy and state regulation of tourism business legalization. E-mail: pea.znu@mail.ru
} 


\section{YOUTH EMPLOYMENT IN REGIONAL ECONOMIC}

such badly needs better integrated management and improvement of the basic employment forms, since employment process has its direct impact on the professional expectations of the youth and their fuller integration into the society.

The available now organizational-economic mechanism which is supposed to facilitate the process of employment among young citizens of the Republic is mostly spontaneous in its functioning. Thus, it is not able to timely and effectively address the challenges Crimean youth is facing under the new configuration of the regional labour market, which significantly limits employment opportunities.

The purpose of this study is to offer an improved organizational-economic mechanism to facilitate the process of effective youth employment at Crimean labour market so that to ensure more sustainable socioeconomic development of the whole Republic.

According to this goal above the authors have formulated the following tasks:

- on the basis of the carried out questionnaire survey to reveal the objective needs of the employers in the region regarding potential workers among the youth, as well as the needs and preferences of young people concerning the effectiveness of the employment process;

- to characterize the potential forms of partnership at the local labour market which may promote youth employment in the Republic of Crimea;

- to improve organizational-economic mechanism aimed at ensuring productive employment for the youth population of the Republic.

Hypothesis 1: Studying the local labor market would allow identifying the main causes for imbalances at the labour market, influencing the process of youth employment promotion.

Hypothesis 2: Partnerships at the labour market provide more stability and also more constructive relationship between the main actors, thus also having a direct impact on the promotion of youth employment.

Hypothesis 3: Effective organizational-economic mechanism is able to stimulate productive employment of the young people and allows a conceptually more reasonable approach to the solution of the issues related to effective employment of young citizens in the Republic of Crimea.

\section{Literary Review}

Under "employment" as such many researchers, including J. P. Orlovsky (Orlovsky, 2014) understand the system of organizational, legal and economic measures undertaken by the state to ensure work opportunities for its citizens.

Professor Marion Y. V., describing the key properties of employment, formulates its basic characteristics (Marion, 2013) as follows: under the employment this scientist, first of all, understands a specific social activity, which has such features as consciousness, productivity, public character. The main social actors are individuals, social institutions and social organizations; and, secondly, employment includes socioeconomic activities resulting in satisfaction of social and economic needs of the individual and the society.

Under employment the authors of this particular study understand a certain system of measures aimed at providing employment for all age groups in accordance with their abilities, level of education, professional training, and complying with the current labour legislation. 
The notion of organizational-economic mechanism should be also specified here. Many scientists have dedicated their scientific works to this notion, including Nobel Laureates Leo Hurwicz, Roger Myerson, Eric Maskin. All of them have made significant contributions to the development of the theory of economic mechanisms, development of conceptual and technical foundations for the economic mechanism; description of optimal auctions; the wording of the main tasks in its implementation; identification of effective mechanisms and schemes for economy's regulation; defining the optimal framework for the state intervention in the economy (Izmalkov et al., 2008; Dovbenko et al., 2011).

In his turn, academician Abalkin L. I. examined it closely together with the economic mechanism as a separate subsystem of the relations ensuring production functioning (Abalkin, 2000).

Some other experts in the same field have concentrated their attention on the formation and management of organizational-economic mechanism for certain specific types of economic activities (Akopashvili, 2011; Vikhrov, 2012).

The team of authors under the guidance of Astapova G. V. has described the role of the analyzed corporate governance mechanism under the conditions of reforming the state economy (Astapova et al, 2001).

Our previous study (Polishchuk, 2016) has also proposed a new organizationaleconomic mechanism for the labour market regulation aimed at achieving a better balance between the processes occurring at the labour market.

The importance of the studies examining the mechanisms at the labour market cannot be denied, but taking into account today's transformational processes in the economy of Crimea, there is a need to develop the most reasonable and effective organizational-economic mechanism, able to create the conditions for effective youth employment in the Republic of Crimea.

\section{Methodology of the Study}

To test the first hypothesis related to studying the labor market in general (its demand and supply) in the region we have conducted a questionnaire survey among the managers of organizations (enterprises). Its key purpose was to collect information about the opinions and expectations of the local employers regarding the quality of training provided today for young specialists.

In the course of this survey conducted from September 2014 to December 2015, we have also interviewed managers of small, medium and large organizations (enterprises) of various forms of ownership (state, municipal and private) operating in the municipalities (urban districts) and also rural settlements of the Crimean region (Tsokhla et al., 2015).

The size of our sample was 2003 organizations. The structure and the volume of sample is sufficient enough and is also representative for assessing the situation in the Republic of Crimea as a whole.

Processing of the questionnaires' data was carried out using SPSS 13.0 for Windows.

\section{Results}

After studying the market of youth labour in the Republic of Crimea and the process of interaction between its main actors the authors of this research may state that there is an 


\section{YOUTH EMPLOYMENT IN REGIONAL ECONOMIC}

obvious necessity to improve the current organizational-economic mechanism affecting the employability of young people in this region.

Organizational-economic mechanism, in this particular context, means a set of basic principles, tasks, methods, tools and trends that can not only increase the competitive advantage of youth, but can also ensure more opportunities for youth employment at the local labour market.

Such goals' setting necessitates solving some other, no less important problems related to today's functioning of the labour market in Crimea. The main tasks in this regard we see as follows: increasing the rate of economic activity of all working-age population; reducing the number of young people that are economically inactive (outside the labour force) and being desperate because of a long stay without work (no matter what is the reason); further development of labour potential of the youth according to the needs of the regional labour market; improving the quality and the competitiveness rate of the young labour force; overcoming poverty among the youth; creation of better conditions for self-employment among the youth of the region in question; provision of trainings designed specifically for young people and concerning the active job search, promotion of more effective employment etc.

While improving the conceptual foundations of this mechanism of significant importance would be the following principles: parity, adaptability, consistency, complexity, sociality, dynamism, innovation, variation. All of them form the basis for the organizationaleconomic mechanism of the labour market management. In turn, formation of this mechanism allows achieving the main employment goal through the development of clear employment and labor guidelines.

The next step concerns the adjustment of the existing organizational-economic mechanism and identifying the main groups of methods, tools and priority directions influencing the employment of young people. This, in turn, would contribute to the creation an appropriate working environment and more rational use of labour force of the young people.

Of significant value for the improvement of the analyzed mechanism are also the legal methods that determine the regulatory and legal framework concerning the labour relations between the main actors of the labour market and young people especially.

Special place in this mechanism should be given to administrative methods, namely, establishment of rights, basic norms of labour relations at the labour market of young people, guarantees and benefits for young people who are frequently in need of special protection when it comes to employment.

Organizational methods in the design of this mechanism include: creating appropriate social and economic conditions for all actors at the labour market; development of effective methods for forecasting the needs for qualified young staff; promotion of young professionals; organization of career guidance for the younger staff etc.

The role of economic methods in the improvement of the studied mechanism concerns mostly the creation of economic incentives (tax incentives for organizations not only for creating, but also for preserving the existing jobs for young professionals; encouraging the development of small businesses; promotion of the youth labor mobility; promotion of youth self-employment; government orders to educational organizations concerning the specific qualifications with all necessary competencies etc.). 
Taking into account the contemporary conditions of regional development, adjustment of the existing organizational-economic mechanism and updating the institutional structure involves consideration of the methods that directly involves various related institutions (state and regional authorities, regulatory labor laws, trade unions, unions of employers, recruitment agencies etc.) that have direct impact on the development of all these partnerships.

According to the authors of this study, effective organizational-economic mechanism could not function without advanced information methods and their instruments which together are supposed to create the information system that affects the behavior of actors at the labour market, promoting their interaction by means of providing information on the current state of the market, business activity of the employers, quantitative and qualitative characteristics of the youth's labor potential, overall socioeconomic situation in the region etc.

Another component, also aimed at improving the organizational-economic mechanism facilitatinf the effective employment process should include the priority areas, the implementation of which will create proper conditions for achieving the main goal of the mechanism - to increase the employment potential of youth at the labour market, its level of competitiveness and well-being among the working population overall.

\section{Conclusions and recommendations}

Studying the process of youth employment in this particular case included questioning the main actors of the labour market and identifying the main causes of the current imbalance at the market (dissatisfaction of employers with training of young people, especially recent graduates; lack of information among young people about the actual situation at the labour market in the region at the time when they are starting their university education; discrepancy between the demand for young specialists on the one hand and the offer at the labour market on the other; obvious difficulties with finding a job directly related to the degree and specialization obtained by a young professional). Therefore, we can assume that the hypothesis \#1 is proved.

From the analysis of information on the distribution of graduates by the level of professional education, the number of unemployed youth aged 14 to 24 y.o., in search of a primary place of work, the average level of youth employment, it is clear that there is a need to develop partnerships for promoting youth employment in the Republic of Crimea. Such partnerships must be well coordinated, constructive and mutually beneficial for all stakeholders that have a direct impact on the solution of the labour market problems. With such a blurry result, we find hypothesis \#2 to remain questionable.

As it has been established in the course of this research, the first two hypotheses prove, to some extent, the initial assumption of the authors concerning the insolvency of the current organizational-economic mechanism of Crimean labor market. Obviously, the latter is not able to address, timely and effectively, the challenges it is facing. Thus, this market is in need of significant improvements that will allow at least approaching the solution of the issues related to the effective employment of young citizens at the labour market of the Republic of Crimea. From this it follows that the hypothesis \#3 is proved.

Taking into account the conducted research results and conclusions, the authors would like to offer the following recommendations: 


\section{YOUTH EMPLOYMENT IN REGIONAL ECONOMIC}

- to implement a brand new regional policy in the field of youth employment promotion so that it will be more aimed at ensuring free choice of employment, protection of labour rights of the young people, providision of the first workplace to all graduates etc.;

- to develop partnerships between the main actors of the labor market for more efficient promotion of youth employment and stronger joint action overall;

- to introduce an improved scheme of organizational-economic mechanism, which will allow not only a new, conceptually more reasonable approach to the solution of the issues related to more effective employment of young citizens in the Republic of Crimea, but will also stimulate the development processes at the labour market overall, taking into account various economic and social constraints relevant specifically for the Republic of Crimea.

\section{References}

Abalkin, L.I. (2000). Selected works: volume II. On the road to reform. Economic mechanism of a developed socialist society. A new type of economic thinking. Restructuring: pathways and challenges. Moscow: Economics, 917.

Akopashvili, P.T. (2011). Formation of the organizational-economic mechanism of corporate governance system in the industry. Economic science, 10(83): 94-96.

Astapova, G.V., Astapova, E.A., Loiko, D.P. (2001). Organizational-economic mechanism of corporate governance in modern conditions of reforming of economy of Ukraine. Donetsk: M. Tugan-Baranovsky University Publishing, 528.

Dovbenko M.V., Osik Y.I. (2011). Modern economic theory. Moscow: Academy Of Science, 305.

Izmalkov, S., Sonin K., Yudkevich, M. (2008). The theory of economic mechanisms. Economic issues, 1: 4-26.

Vikhrov, M.S. (2012). The essence of organizational-economic mechanism of management of agribusiness. Problems of development of foreign economic relations and attraction of foreign investments: regional aspect, 2: 66-68.

Marion, Y.V. (2013). Analysis of the essential characteristics of employment as a control object. Theory and practice of social development, 10: 78-82.

Orlovski, J.P. (2014). Labour law of Russia. Moscow: Yurayt, 854 p.

Polishchuk, E.A. (2016). The organizational-economic mechanism of regulation of the labour market of youth of the Russian Federation. Basic research, \#4-2: 424-430.

Tsokhla, S.Y., Simchenko, N. A., Polishchuk, E.A. (2015), Regional policy in the sphere of promotion of youth employment (on the example of Crimea). The globalization of the economy and Russian industrial companies: 173-176.

Paper submitted

Paper accepted for publishing

Paper published online
10 November 2017

12 February 2018

30 March 2018 